\title{
From Behind the Curtain to Physicians with a Nerve of Steel...The Transition of an Anaesthesiologist During the Pandemic
}

\author{
Kaminder Bir Kaur ${ }^{1}$, Vishal Mangal ${ }^{*}$ \\ ${ }^{1}$ Department of Anaesthesiology \& Critical Care, ${ }^{2}$ Department of Internal Medicine, \\ Armed Forces Medical College, India
}

\begin{abstract}
Dear Editor,
A patient under general anaesthesia is like a passenger on board to a flight for his surgery with an anaesthetist as the pilot. The anaesthetist is responsible for the smooth take-off, stable journey, and hassle-free landing. That is how an anaesthesiologist plays a role in handling a patient when he is anaesthetized. Anaesthesiology was an infamous specialty till this Coronavirus disease (COVID-19) pandemic hit worldwide - the specialist who was always behind the curtains.
\end{abstract}

During the COVID-19 pandemic, one specialty of modern medicine that has emerged into the limelight is Anaesthesiology. The "Anaesthetists" became the front-line warriors of this pandemic. Anaesthetists are managing critically ill patients in the ICU as well as nonCOVID-19 patients in the operating theatre. Everyone has suddenly recognized the forefront doctors who emerged from behind the impenetrable walls of operation theatre. ${ }^{1}$

The airway management, the backbone of an anaesthesiologist, became critical and the most prime call for saving the patients severely affected by COVID-19. ${ }^{2,3}$ In securing the airway, a highly infectious, aerosol-generating

*Correspondence: Vishal Mangal

E mail: vishal_rimshi@rediffmail.com

https://orcid.org/0000-0002-7030-5745

Received: 2020.12 .04

Accepted: 2021.09.08

DOI: https://doi.org/10.4038/slja.v29i2.8724 procedure, the anaesthesiologists kept the shield on and continued taking care of the patients. The innovation in doing the age-old procedures in a newer way was a herculean task. The modification of the intubation procedure, placement of arterial lines in the prothrombotic state of COVID-19 were few of the challenges accepted and claimed well.

The critical care patient load increased over and above the regular medical and surgical intensive care units. The anaesthetist's proficiency in oxygen therapy, non-invasive ventilation, intubation, invasive ventilation, extracorporeal membrane oxygenation, placing central lines, and most risky cardiopulmonary resuscitation is being used for treating the most critical patients of COVID-19.

From the confirmation of endotracheal tube placement to the detection of pleural effusion or pneumothorax in a patient, which could have been easily identified with a stethoscope, was to be learned in new ways with personal protective equipment (PPEs) on. The ultrasonography (USG) came for a save. The anaesthesiologists have to go a step beyond their capabilities, learned the USG to couple up their clinical abilities. This pandemic is affecting the physical health of the anaesthesiologist and taking a toll on their mental health. ${ }^{4}$ Nevertheless, they emerged as strong CORONA warriors to fight this battle.

The anaesthesiologists became the war façade in front of this deadly virus. They also took up the responsibility to prepare the health care workers team to stand as a wall between the virus and the patients. The rigorous training on donning and doffing of PPEs, the awareness of the use of masks and gloves in health care workers, the 
general concept of disinfecting the surfaces done by them, prepared the team.

The pandemic has taught and shown the world that "the buck stops at us." The magnitude of this specialty will encourage so that the world gets more and more new anaesthesiologists to handle such situations in the future. Anaesthesiologists have proved that they are a vital pillar of the medicine fraternity by working beyond the operating rooms with the nerves of steel in this COVID-19 pandemic.

\section{References}

1. Bhatnagar S, Mehdiratta L, Karthik A R. Coronoa pandemic: Bringing Anaesthesiologist's professional role and other skills to the fore. Indian $J$ Anaesth 2020: 64. Suppl S2:87-90
2. Ortega R, Chen R. Beyond the operating room: the roles of anaesthesiologists in pandemics. $B r \quad J \quad$ Anaesth. 2020; 125(4):444-447. https://doi.org/10.1016/j.bja.2020.06.00 5

3. Patwa A, Shah A, Garg R, et al. All India difficult airway association (AIDAA) consensus guidelines for airway management in the operating room during the COVID-19 pandemic. Indian J Anaesth 2020; 64:107-15

4. Singh A, Khanna P. Anesthetist and pandemic: Past and present [published online ahead of print, 2020 Aug 10]. Trends in Anaesthesia \& Critical Care. 2020 https://doi.org/10.1016/j.tacc.2020.07.01 1 